\title{
Um projeto de inclusão digital como estratégia de relações públicas'
}

\section{A design of digital inclusion as a strategy for relations public}

\author{
Valmor RHODEN \\ Universidade Federal do Pampa (Brasil) \\ valmor@unipampa.edu.br \\ Juliana Lima Moreira Rhoden \\ Universidade Federal do Pampa (Brasil) \\ juli.rhoden@gmail.com \\ Patricia Renner de Oliveira \\ Acadêmica de Relações Públicas e bolsista do projeto (Brasil) \\ tati renner@hotmail.com
}

Recibido: $30 / 7 / 2013$ Aceptado y Publicado: $30 / 9 / 2013$

\section{Resumen}

O presente artigo é uma reflexão sobre um projeto de extensão intitulado Projeto de Inclusão Digital proposto pelo curso de Relações Públicas Ênfase em Produção Cultural da Universidade Federal do Pampa - Unipampa, campus São Borja em parceria com a loja Clean Informática e com Instituto Federal Farroupilha. O projeto que teve a sua primeira edição no ano de 2012 objetivou contribuir para a inclusão digital de alunos de escolas públicas do entorno da universidade. Como metodologia de trabalho foi proposto e realizado na primeira edição oito encontros que ocorreram no laboratório de informática da universidade, nos quais foram abordados conteúdos de nível básico do Windows e da internet. Através desta experiência prática pode-se constatar a importância das ações de extensão, visando à inclusão de alunos que ainda tem um acesso limitado as novas tecnologias. O Projeto também deu visibilidade à imagem da empresa parceira através das atividades e funções de Relações Públicas. Atualmente este projeto vem sendo ampliado. No ano de 2013 mais quatro turmas estão participando das aulas, o que demonstra a relevancia.da inclusão digital no processo de desenvolvimento tanto educacional como social e para a própria imagem da empresa envolvida, além da aprendizagem que proporciona aos alunos bolsistas do curso de Relações Públicas.

\section{Abstract}

This article is a reflection on an extension project titled Digital Inclusion Project proposed by the course Public Relations Emphasis in Cultural Production, Federal University of Pampa - Unipampa, campus São Borja in partnership with the store Computer Clean and Federal Institute Farrukhabad. The project which had its first edition in 2012 aimed to

\footnotetext{
Facultad de Ciencias de la Información - Universidad de La Laguna

Avenida César Marique, s/n; Campus de Guajara

38071 La Laguna, Tenerife (Islas Canarias - España)
} 
contribute to the digital inclusion of public school students around the university. Like the work methodology was proposed and realized in the first edition eight meetings that took place in the computer lab at the university, it dealt with content-level Windows and the Internet. Through this practical experience can note the importance of extension actions, aiming at the inclusion of students who still have limited access to new technologies. The Project also gave visibility to the partner company's image through the activities and functions of Public Relations. Currently this project is being expanded. In 2013 four more classrooms are participating in the classes, which demonstrates the importance of digital inclusion in the process of both educational and social development and the very image of the company involved, beyond learning that provides students Fellows Course Public Relations.

Palabras Clave: Inclusão digital; Relações Públicas; Estratégias.

Keywords: Digital Inclusion; Public Relations; Strategies.

\section{Introducción}

Nos dias atuais vivemos num mundo com grandes avanços tecnológicos em diferentes áreas do conhecimento. O crescimento das novas Tecnologias da Informação e Comunicação a TICs, mais especificamente na área da informática, comunicação e da internet, geraram novas formas de conhecimento, lazer, raciocínio e a interação com diferentes pessoas, costumes e culturas. Porém esse crescimento não chegou a todos com igualdade de acesso, causando assim uma exclusão digital.

A problemática da exclusão apresenta-se como um dos grandes desafios na atualidade sendo de grande relevância as iniciativas que tenham como objetivo a inclusão digital, a fim de assegurar aos cidadãos a efetivação de seus direitos e o exercício de uma cidadania plena. Segundo o IBOPE em pesquisa no ano de 2011, 73,9 milhões de pessoas no Brasil tinham acesso a internet havendo um crescimento de apenas $9,6 \%$ em relação ao ano de 2009.

Para incluir as pessoas de fato no meio digital é necessário dar não apenas um computador ligado a internet, mas o conhecimento de como utilizá-lo, a fim de que sejam um instrumento de construção e exercício de cidadania e melhore as condições de vida de uma determinada região ou comunidade.

Segundo o autor Warschauer a:

...exclusão digital caracteriza-se não apenas pela falta de acesso físico a computadores e á conectividade, mas também a recursos adicionais, que permitem 
que as pessoas utilizem a tecnologia de modo satisfatório, com habilidades cognitivas para potencializar o seu uso (2006, p. 23).

Neste sentido, é imprescindível a mobilização de esforços coordenados de empresas, universidades, governo e sociedade civil para a criação de condições ao fortalecimento da consciência social e na capacidade de identificar, diagnosticar e capacitar sujeitos e agentes na inclusão digital.

Este artigo traz reflexões de uma experiência bem sucedida de um projeto de inclusão digital proposto pelo curso de Relações Públicas em parceria com loja Clean Informática. A empresa parceira, além de ter contribuído com a inclusão digital de alunos do entorno da Universidade teve valor agregado a sua imagem por ter participado nesta ação e ter tido a oportunidade de ser reconhecida. Os Profissionais de relações públicas, na figura dos discentes que atuaram no projeto mediaram às estratégias de comunicação e divulgação e execução do projeto e a mensuração dos resultados alcançados.

A empresa pode mostrar que se preocupa com questões sociais que envolvem a comunidade onde esta inserida e que de alguma maneira pode contribuir com a transformação social e o exercício de cidadania através de sua parceria.

Como aponta Wey:

Boas relações com a comunidade facilitam a aceitação de uma empresa e afastam desconfianças. Fazem com que os públicos da comunidade sintam que a empresa representa importante papel na vida social da comunidade. $E$ ambos devem assumir suas respectivas responsabilidades, sem esperar benefícios a expensas de prejuízo do outro (1986, p. 76).

O profissional de relações-públicas é o gestor desse relacionamento, é ele quem vai criar estratégias e executá-las reforçando a imagem da empresa para seu público assim como nos reforça Kunsch (2009, p. 246) que: "de forma concisa, as relações públicas contribuem Sociedad Latina de Comunicación Social para a efetividade de uma organização quando buscam conciliar os objetivos desta com as expectativas dos públicos estratégicos."

Para alcançar essa imagem positiva da empresa perante a comunidade é necessário haver uma gestão estratégica do relacionamento entre ambos, aonde isso irá acontecer através de uma comunicação simétrica que prevaleça a verdade, o diálogo, a transparência e a responsabilidade social que a empresa efetivamente realiza. "Essa comunicação caracterizase pela compreensão mútua, onde o diálogo e o equilíbrio entre organização e seus públicos são priorizados", além de administrar os conflitos mediante a mudança de comportamento de ambas as partes (Ferrari, 2002, p. 04). 


\section{Relações Públicas: conceito, estratégia e a construção da imagen}

As relações públicas entram no segundo século de sua existência, trazendo consigo um conceito amplo. Por ser uma profissão com mais de um século de existência no mundo, o profissional deve estar preparado às mudanças que ocorrem na sociedade com o passar do tempo e com isso o conceito e a atividade vão agregando novas competências. Para Kunsch a profissão tem os seguintes objetivos:

O objetivo das relações públicas é estabelecer, desenvolver e manter, de forma planejada, vínculos, relacionamentos diretos, gerais ou especializados, com pessoas, organizações, públicas e privadas, públicos e sociedade, com vista a traduzir esses relacionamentos em benefícios para as partes envolvidas (2009, p. 246).

Ainda nesse contexto Ferrari nos ressalta que:

As mudanças que estão ocorrendo no cenário mundial e a rapidez com que a sociedade e as organizações estão interagindo vêm contribuindo para a legitimação dessa profissão como gestora de comunicação e fonte de consultoria para a alta administração. Por outro lado, os caminhos a serem tomados com relação a sua performance comunicacional implicam no reconhecimento de seu caráter estratégico (2009, p.161).

Manter um bom relacionamento da empresa com seu público interno e externo, gerar e manter um bom relacionamento de comunicação e bem estar com os colaboradores, já que estes passam mais na empresa do que em casa ou em qualquer outro lugar, fazendo com que estes se sintam parte efetiva dentro da organização e criar uma imagem positiva da empresa perante a comunidade são também algumas das funções e estratégias das Relações Públicas. É erro comum ao se definir a profissão para as pessoas que não a conhecem ou a reconhecem apenas como assessoria de imprensa, o que é na verdade apenas uma de suas ferramentas, mas seu enfoque maior é o relacionamento com os diferentes públicos de interesse e na formação de imagem de uma organização com seus públicos.

Como o Relações-Públicas é o gestor da comunicação, ou seja, deve fazer fluir informações com os públicos da organização, e assim vai criar uma imagem positiva da organização. É a área que vai dar foco para essa imagem através de ações e estratégias mais pertinentes para alcançar os públicos de interesse. Para Marconi:

Descrevem-se os profissionais de Relações Públicas como aqueles que fabricam a imagem, e seus clientes e empregadores os contratam porque estão preocupados 
com suas próprias imagens e de como eles são vistos pelo público. Imagem é sinônimo de percepção e, na opinião de muitos, o intervalo entre percepção e realidade existe e pode ser significativo (2009, p.72).

A imagem construída tem que ser reflexo da realidade, pois a percepção às vezes pode estar ligada a algum fato que não é de real ou ilusório, e cabe ao profissional de Relações- Públicas mostrar essa diferença. Como a imagem passa e representa a verdade sobre a organização ela não deixa de representar a reputação da mesma perante a sociedade em que está inserida, com isso não pode ser vinculada a algo que de fato não acontece na organização. Marconi (2009, p. 72) ainda nos descreve que "seja com uma empresa ou organização, seja com um indivíduo, a verdade é que as ações falam mais alto que as palavras, mas as palavras, sim, são importantes ao se criar e manter uma reputação". É preciso ter coerência na divulgação ou em outra forma/estratégia de construção da imagem. Ela precisa refletir a realidade das ações/posicionamento.

Para se alcançar essa imagem o profissional de Relações Públicas precisa de estratégias. As ações estratégicas são direcionadas para a realização de ações comunicacionais para grupos que afetam a organização ou podem ser afetados, de alguma forma, por ela. Para essa comunicação fluir ela tem que ter um planejamento e ser eficaz assim como nos ressalta Grunig:

Para que um programa de Relações Públicas seja eficaz, é necessário que um profissional o gerencie estrategicamente. È necessário que o programa seja orientado aos públicos que exercem maior impacto sobre a organização. Esse gerente estratégico aconselha a alta administração da organização a respeito das consequências de decisões organizacionais sobre os públicos, avaliando se tais decisões podem prejudicar ou beneficiar os relacionamentos com esses públicos (2009, p. 22).

A estratégia pode ser definida mais claramente nesse sentido como a habilidade comunicacional essencial para a realização eficaz da própria comunicação da organização com seus públicos. Essa estratégia deve além de tudo buscar o equilíbrio do bem-estar social visando a melhora da qualidade de vida, de seu público interno como o externo, e uma relação mais justa que consiga agregar mais valores. A estratégia voltada para ações de bem-estar para a comunidade onde a empresa está inserida reverterá em imagem mais positiva da organização. As ações sociais são uma boa forma de fortalecer isso. Nos días atuais as pessoas não compram mais apenas produtos ou serviços, mas também pela identificação que estas têm com a forma de pensar e agir da organização

Facultad de Ciencias de la Información - Universidad de La Laguna

Avenida César Marique, s/n; Campus de Guajara

38071 La Laguna, Tenerife (Islas Canarias - España) 
perante os públicos. Nesta perspectiva surgiu o projeto de inclusão digital em São BorjaRS.

\section{O Projeto de inclusão digital em São Borja}

\section{O início do projeto}

O projeto de Inclusão Digital foi criado e implementado em 2012 pelo curso de Relações Públicas - Ênfase em Produção Cultural da Universidade Federal do Pampa UNIPAMPA.

\section{As parcerias}

Inicialmente apenas com a empresa Clean Informática e o IFF. Devido a grande repercussão do mesmo (procura pelo curso), ele foi ampliado, transformado em projeto de extensão e com mais apoiadores e parceiros. Já em 2013, além destas acima, foi necessária a busca de novos parceiros, pois o projeto cresceu e exigiu novas demandas. A empresa de ônibus da cidade, Santa Ignês Transportes viabilizou os vales transportes para as pessoas se locomoverem e participarem das aulas. A Vartell Gestão Webempresa de cursos de informática disponibilizou as apostilas, um novo recurso que a edição anterior não tinha.

\section{Metodología y discusión}

$\mathrm{Na}$ sua primeira turma foram atendidos vinte alunos da Escola Estadual de Ensino Fundamental Tusnelda Lima Barbosa que fica localizada no bairro do Passo a poucas quadras da universidade. As aulas aconteceram no laboratório de informática da Unipampa, aos sábados. Na primeira aula tivemos uma breve fala dos diretores da empresa e da coordenadora do campus, o mesmo aconteceu na entrega dos certificados para os alunos. Foi um total de oito encontros com aula. O projeto teve uma boa visibilidade e aceitação na cidade.

Em função disso ele foi transformado em Projeto de Extensão pela Universidade para o ano todo de 2013 serão mais quatro turmas beneficiadas, de diferentes perfis e situações sócio-econômicas. Até o momento já foram duas turmas finalizadas. Os horários das aulas foram alterados para os sábados à tarde, no laboratório de informática da Unipampa.

O profissional de relações-públicas pode usar dessa ferramenta para agregar valor, responsabilidade social e cidadania a marca da empresa aonde atua. As pessoas buscam 
a empresa não mais por produtos, mas também por a identificação que têm com a mesma, se esta se importa e faz algo pela sociedade onde está inserida. Nesse contexto Cruz nos ressalta que:

Do ponto de vista de uma empresa com responsabilidade social, investir em programas de inclusão digital significa entender "solidariedade" não só como mero conceito assistencialista, mas como promoção de oportunidade para a produção e a disseminação de conhecimento e renda (2004, p.10).

As empresas precisam focar mais na comunidade onde estão inseridas ajudando-a a crescer e melhorar a condição de vida das pessoas, o que consequentemente vai agregar valor a sua imagem. Uma dessas formas é a empresa contribuir para reduzir a exclusão digital, como nos diz Cruz:

Existem várias formas de as empresas contribuírem para reduzir o problema da exclusão digital. Entre elas, estão a doação de computadores, o estímulo ao voluntariado corporativo, o patrocínio do desenvolvimento de tecnologias de incluso digital, a promoção da capacitação tecnológica de professores de escolas públicas, o financiamento de computadores e acesso à Internet em escolas públicas e o apoio a centros comunitários e a escolas de informática, que podem ser instaladas tanto na própria empresa quanto nas comunidades onde estão inseridas (2004, p.43).

As aulas do projeto são ministradas por alunos(as) do Curso Técnico em Informática do Instituto Federal Farroupilha. Cada turma conta com dois monitores. Os conteúdos são adaptados, dependendo das necessidades específicas das turmas. Esses conteúdos são o básico das principais ferramentas do Windows que são: funções básicas, Word, Excel, Antivírus, Power Point e como elas irão usar o computador para fazer pesquisas e se comunicar através do E-mail e Redes Sociais. Porém a turma da terceira idade requer um diferencial em seus conteúdos, pois ela usará o computador mais como uma forma de inserção, informação e comunicação com outras pessoas, círculo de amizades e familiares.

O Projeto de extensão ganhou uma identidade visual própria, criada por um acadêmico do Curso de Publicidade e Propaganda da Universidadeii. A importância de ser ter uma identidade própria é ressaltada por Strunck quando diz que:

As identidades visuais são um instrumento fundamental nas políticas de marketing das organizações. São a expressão de sua identidade e a garantia de responsabilidade perante a sociedade. Cuidadosamente criadas e implementadas, traduzem exatamente a forma pela qual as empresas gostariam de ser vistas por 
seus públicos externo, seus clientes e fornecedores, e interno, os que nela trabalham (1989, p. 44).

A marca traz um conceito que destaca a importância do Projeto com fonte de novos conhecimentos e de novas possibilidades, a partir de referências que evidenciam a presença da Universidade como principal promotora. Entende-se a inclusão em ambientes digitais como um processo contínuo, de aprendizagens constantes. Nesse sentido, torna-se importante a utilização de elementos que possam representar esse caráter de dinamicidade que os espaços digitais evocam. Levando em conta esses direcionamentos, foram definidos os elementos (cores, tipografia, círculos e intersecção) que compõem a marca (figura 1).

A cor verde expressa equilíbrio e esperança e sua utilização em contextos digitais é explicada, principalmente, em virtude da referência às placas de computadores. A escolha por uma tonalidade mais clara acentua aspectos importantes do universo digital, como a dinamicidade, o movimento, a transformação. O preto expressa estabilidade, segurança e credibilidade, aspectos do Projeto Inclusão Digital que são reforçados pela marca - a rigidez e a sobriedade do preto são atenuadas pela fonte, que possui traços modernos e flexíveis.

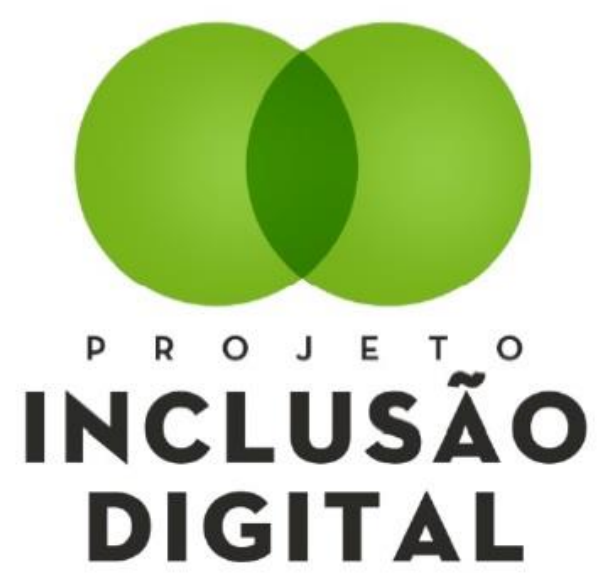

Figura 1: logomarca do projeto.

Para referenciar os propósitos do projeto (ensino e extensão) foram utilizados os dois círculos. A intersecção, como ocorre em todo e qualquer conjunto, representa o somatório dos elementos: simboliza, portanto, a efetivação dos esforços do Projeto Inclusão Digital. 
O espaço de intersecção coloca em evidência, por um lado, os sujeitos envolvidos com o Projeto (alunos, professores, colaboradores) e, por outro, as experiências, as posibilidades e os conhecimentos adquiridos.

Ao final de cada edição/curso será aplicada uma pesquisa de opinião com os participantes para saber quais pontos deverão ser melhorados para as turmas futuras. No questionário serão abordados todos os itens que constituem o projeto como: espaço físico, acessibilidade, computadores, monitores e conteúdos.

\section{Conclusiones}

Fica assim eminente a necessidade das pessoas passarem a ser incluídas digitalmente, a fazerem parte efetivamente da sociedade onde estão inseridas e das empresas contribuírem de alguma forma para essa inclusão, seja na criação de projetos como esses, na doação de computadores para associações, se tornando parceiras de projetos já existentes ou então incentivando o voluntariado em seus colaboradores.

O profissional de relações-públicas pode/deve orientar a empresa para qualquer uma dessas formas de inclusão digital, além de apoiar projetos já existentes e criar um projeto, como é o da inclusão digital e São Borja, que foi criado como estratégia de Relações Públicas.

Os casos bem-sucedidos da iniciativa privada poderiam servir de base para iniciativas mais amplas do governo". Se houver um maior interesse de ambos a realidade da exclusão poderá ser combatida com mais rapidez e não dependerá apenas do governo, pois mesmo havendo iniciativas deste ainda é um processo que caminha devagar no Brasil.

Com essa união a barreira da exclusão social também estaria sendo eliminada da vida de muitas pessoas e a cidadania seria exercitada com plenitude de direitos, pois as pessoas estarão aptas a participar mesmo que a partir do virtual, que faz parte do real, e assim buscar seus direitos e reivindicá-los de uma forma que gera mais visibilidade e que pode ser compartilhada para o mundo todo.

Os projetos de inclusão devem são ótima ferramenta de relações públicas, pois visibiliza a empresa, a relaciona com outros setores da sociedade e as pessoas a reconhecem comom elemento que as propiciou a se incluírem digitalmente. Isso numa sociedade da era digital é representativo. Isso ao mesmo tempo é uma forma de atualizar as ações de responsabilidade social às novas demandas que surgem. 


\section{Bibliografía}

BECKER, Maria Lúcia. Inclusão digital e cidadania; as possibilidades e as ilusões da solução tecnológica. Ponta Grossa: UEPG, 2009.

CRUZ, Renato. O que as empresas podem fazer pela inclusão digital. São Paulo: Instituto Ethos, 2004.

GRUNIG, James; FERRARI, Maria Aparecida; FRANÇA, Fabio. Relações Públicas: teoria, contexto e relacionamentos. São Paulo: Difusão, 2009

MARCONI, Joe. Relações Públicas: O guia completo / Joe Marconi. Tradução Anna Maria Dalla Luche. - São Paulo: Cengage Learning, 2009.

PELLANDA, Nize. M. C.; SCHLÜNZEN, Elisa. T. SCHLÜNZEN, Klaus. S. J.(orgs.). Inclusão digital: tecendo redes afetivas/cognitivas. Rio de Janeiro: DP\&A, 2005.

RAMOS, Sérgio. Tecnologias da Informação e Comunicações: conceitos básicos. Disponível

em:<http://livre.fornece.info/media/download_gallery/recursos/conceitos_basicos/TICConc eitos_Basicos_SR_Out_2008.pdf> Acessado em: 16 de abril 2013.

SIVEIRA, S. A. Exclusão Digital: a miséria na área da informação. São Paulo: Fundação Perseu Abramo, 2001.

STRUNCK, Gilberto Luiz. Identidade Visual: a direção do olhar. Rio de Janeiro: Europa Emp, 1989.

WEY, Hebe. O processo de relações públicas/ Hebe Wey. - São Paulo: Summus, 1986.

\section{Forma de citar este artículo en bibliografías}

Rhoden, V.; Moreira Rhoden, J. M.; Renner de Oliveira, P. (2013): "Um projeto de incluso digital como estratégia de relações públicas", en Revista PANGEA, 4, páginas 126 a 135. Red Académica Iberoamericana de Comunicación. Recuperado el de de 2 de: http://www.revistapangea.org

\footnotetext{
${ }^{i 1}$ Artículo producto de una Ponencia presentada en el VI Encuentro Panamericano de Comunicación COM PANAM 2013 celebrado la Escuela de Ciencias de la Información de la Universidad Nacional de Córdoba (Argentina), durante los días 5, 6 y 7 de junio de 2013.

ii A criação foi do aluno Paulo Henrique Nunes da Silva com a orientação da professora Damaris Strassburger.
} 